\title{
CONSIDERACIONES TEORICAS SOBRE LA VIOLENCIA SOCIAL EN CHILE (1850-1930)*
}

\author{
IGOR GOICOVIC DONOSO**
}

\begin{abstract}
RESUMEN
En este artículo nos proponemos estudiar los procesos de transición - sociales y culturales - de la sociedad popular chilena de fines del siglo XIX y comienzos del siglo XX, a partir de las situaciones de conflicto que tensionan la relación entre los sujetos populares, el Estado y las élites dominantes. La clave analítica más relevante de este estudio son las manifestaciones de violencia desplegadas por los sujetos populares en diferentes ámbitos espaciales del territorio nacional. Particularmente nos interesa analizar las dimensiones teóricas del motín urbano, el levantamiento minero y el bandolerismo rural.
\end{abstract}

PALABRAS CLAVE: HISTORIA, TEORÍA SOCIAL, VIOLENCIA COLECTIVA

* Este artículo se ha beneficiado de los recursos aportados por los proyectos de investigación, "Violencia social y revueltas populares. Chile, 1850-1912», FONDECYT 1020063 y «Construcción de Estado, formas de disciplinamiento social y violencia colectiva (Llanquihue y Valdivia, 1880-1920)», Proyecto Interno de Investigación Científica y Tecnológica 00301, Universidad de Los Lagos, Osorno, Chile.

** Académico, Departamento de Ciencias Sociales, Universidad de Los Lagos e Investigador CIDPA. E-Mail: igor@cidpa.cl. 


\section{RESUMO}

Neste artigo propusemo-nos a estudar os procesos de transição — sociais e culturais da sociedade popular chilena em fins do século XIX e início do século XX, a partir das situações de conflito, geradoras de tensões nas relações entre os sujeitos populares, o Estado e as elites dominantes. A explicação analítica mais relevante deste estudo são as manifestações de violência realizadas por sujeitos populares em diferentes regiões do território nacional. Particularmente, interessa-nos analisar as dimensões teóricas do motim urbano, a revolta dos mineiros e a formação de grupos de revoltosos armados na zona rural.

PALAVRAS CHAVE: HISTÓRIA, TEORIA SOCIAL, VIOLÊNCIA COLETIVA

\section{ABSTRACT}

In this article, we propose to study the transition processes - social and cultural - of the popular society in Chile at the ending of the nineteenth century and beginning of the twentieth century, starting from the conflict situations that stress the relation between the popular subjects, the State and the dominant elites. The most important analytical key of this study is referred to the manifestations of violence, displayed by the popular subjects in different spatial spheres inside the national territory Particularly, we are interested in analyzing the theoretical dimensions of the urban riot, the mining uprising and the rural banditry.

KEY WORDS: HISTORY, SOCIAL THEORY, COLLECTIVE VIOLENCE 


\section{Presentación}

LOS PROCESOS DE TRANSICIÓN económicos, políticos, sociales y culturales que atraviesan a la sociedad chilena, entre la segunda mitad del siglo XIX y las tres primeras décadas del siglo XX, generaron una serie de tensiones que devinieron en explosiones de violencia social que conmocionaron el orden oligárquico de la época. Las manifestaciones de violencia desplegadas por los sujetos populares en diferentes ámbitos espaciales del territorio nacional - motines urbanos, levantamientos mineros, bandolerismo rural y huelgas generales-, expresaron las profundas contradicciones que atravesaban la relación entre el mundo popular, el Estado oligárquico y la clase dominante.

En este artículo nos proponemos analizar las características fundamentales de la protesta popular urbana y rural en Chile central, durante el período que media entre 1850 y 1930, a objeto de construir una explicación que historice los fenómenos de violencia social. Concurren al efecto una serie de problematizaciones que nos proponemos abordar: ¿qué tipo de manifestaciones específicas asume la violencia social popular durante el período en estudio?, ¿qué sujetos sociales protagonizan la protesta popular?, ¿qué elementos articulan el discurso y la praxis represiva del Estado oligárquico? Para responder estas interrogantes nos proponemos discutir las categorías de análisis que, en torno a la problemática de la violencia, ha desarrollado la historia social.

\section{ESTRUCTURAS Y TRANSICIONES}

Los procesos históricos de transición de la sociedad preindustrial a la sociedad moderna han sido objeto de prolíficos e interesantes estudios en el ámbito historiográfico internacional (Hobsbawm, 2001a, 2001b, 2001c, 2000, 1999a y 1998; Aston y Philpin, 1988; Mayer, 1984; Dobb, 1979). En el tratamiento de estos temas han adquirido especial relevancia las formas institucionales y sociales de adscripción de los sectores populares a los nuevos escenarios políticos, económicos y sociales. Los mecanismos integradores, sean éstos democráticos o coactivos, han cautivado la atención de los investigadores. De la misma manera la reacción popular frente a las compulsiones institucionales o frente a los procesos de integración forzoso han ocupado un lugar importante en la investigación social. Tal es así que problemáticas tales como la revuelta popular premoderna, ha sido tratada abundan- 
temente en los estudios clásicos de Rudé (2004, 1998 y 1988), Thompson (1984), Hobsbawm (2001d, 2001e, 2000 y 1999b), Tenenti (1999), Porter y Teich (1990), Forster y Greene (1984) y Moore (1979). A su vez, las especificidades de la revuelta popular en América Latina han sido abordadas en sus diferentes dimensiones espaciales y sociales en múltiples y rigurosos estudios. ${ }^{1}$ Los más interesantes se hacen cargo de los levantamientos indígenas y campesinos de México (García, 1994; Reyna, 1988; VV.AA., 1987) y sus similares de Perú (O’Phelan, 1995 y 1988; Husson, 1992; Aguirre y Walker, 1990; Ramos, 1990; Stein, 1988; Kapsoli, 1987; Vásquez, 1976) y Bolivia (Antezana, 1999 y 1994; Del Valle, 1990); por su parte las insurrecciones de esclavos han sido objeto de estudio por parte de Fonseca (2003), Chiavenato (2002), Moura (1988) y Reis (1995) para Brasil, y por Aguirre (1993) para el Perú. Los movimientos insurreccionales de la clase trabajadora, cuentan con los incisivos trabajos de Flores (1983) y Pereda (1982), para el caso peruano y los estudios de Bayer (2003 y 2002), Suriano (2000) y Godio (2000), para Argentina.

Pero las revueltas populares para el caso de Chile no han tenido un tratamiento de similar envergadura y profundidad. Ello ha sido consecuencia de la óptica conservadora que ha hegemoneizado los estudios históricos a la hora de analizar las conductas e intervenciones de los sectores populares. De esta manera la presencia del bajo pueblo en la historia de Chile tiende a ser establecida exclusivamente, en su dimensión subordinada o en cuanto comparsa social de las clases hegemónicas, pero rara vez en sus manifestaciones de resistencia y rebeldía (Barros Arana, 1884-1902; Encina, 1983-1984; Eyzaguirre, 1965; Heise, 1974; Vial, 1996). A contrapelo de ello, los estudios de Salazar (1985) e Illanes (1990), nos permiten recrear una imagen distinta, en la cual las compulsiones estatales y elitarias dan origen a un estado de resistencia permanente. De la misma manera, los trabajos de Pinto (1998) y de Grez (1997), contribuyen a precisar los mecanismos de transición de las formas peonales de resistencia y organización a las formas modernas y proletarias de articulación social. Pero en estos casos la protesta popular sólo es abordada de manera parcial. Por otra parte, en los estudios de Valenzuela (1991), Garcés (1991) e Izquierdo (1976) es posible observar un tratamiento en profundidad de la rebeldía popular; ello a pesar que el primero restringe su objeto de estudio

1 Un enfoque general de esta problemática se puede encontrar en la compilación de Eckstein, 2001. 
a un ámbito espacial muy preciso (Curicó), mientras que el segundo y el tercero sólo se hacen cargo de un período histórico muy limitado. Por otro lado los contextos espaciales en los cuales se desenvuelven y sociabilizan los actores populares, han sido abordados de manera rigurosa por De Ramón (1985) y Romero (1997) para el espacio urbano y por Bengoa (1988) para el ámbito rural.

Pese a estos notables avances, consideramos que aún no se ha saldado la deuda con la temática de la transición de las formas de intervención social desplegadas por los actores populares. Particularmente con las formas de rebeldía social desplegadas por los mismos en el contexto de la transición de la sociedad chilena a la modernidad capitalista.

Como lo demuestran los estudios de Salazar (1991, 1990 y 1985), Bengoa (1988) y Pinto (1998) la sociedad chilena decimonónica - particularmente la de la segunda mitad del siglo XIX- es rica en procesos de convulsión social. La transición del modo colonial de producción al modo capitalista operó como contexto de una serie de readecuaciones en las relaciones laborales, en el diseño y construcción de espacio urbano, en las formas de recrear ideológicamente los procesos y los actores sociales y en las formas con las cuales el Estado enfrentaba su rol en la sociedad. Este proceso se acentúa, a partir de la década de 1850, en el marco de una mayor aceleración de los procesos modernizadores. La construcción del tendido ferroviario en la zona central del país (Lacoste, 2000; Thomson y Angerstein, 1997), el auge y expansión de las actividades mineras (Ortega y Pinto, 1990; Vayssiere, 1980), el incipiente proceso de industrialización en los centros urbanos de Santiago y Valparaíso (Carmagnani, 1998; Ortega, 1981), el inició de las migraciones peonales - tanto internas como externas- (Pinto, 1998; Harris, 1997), el impacto de la coyuntura cerealera en la descampesinización de los campos (Bauer, 1970; Salazar, 1985; Bengoa, 1988; Kay, 1992), la escisión de la ciudad patricia y la ciudad plebeya (Romero, 1997; De Ramón, 1985), la pacificación de la Araucanía y el despojo mapuche (Bengoa, 1987), son antecedentes relevantes en el proceso de transformación del mundo social decimonónico.

En este escenario en transformación, los sujetos sociales pertenecientes a los estratos más pobres de la población, adquieren un creciente protagonismo social. La sostenida demanda de mano de obra para cubrir las necesidades de las faenas agrícolas, de los establecimientos mineros o de las obras públicas, colocó como problemática 
fundamental para el Estado y las élites empresariales, el diseñar estrategias de reclutamiento y asentamiento de la fuerza de trabajo. En el centro de dichas estrategias se encuentran los mecanismos de compulsión laboral orientados a fijar a los trabajadores en determinadas actividades productivas; junto con ello se despliegan una serie de iniciativas tendientes a disciplinar las conductas transgresoras de la población $\mathrm{y}$, por otro lado, se elabora un discurso moralizante que pretende intervenir sobre las prácticas culturales y sobre las formas de sociabilización de estos sujetos. Pero las clases populares, particularmente la peonada de origen colonial, tiende a resistir esta triple matriz de intervención. Continúan practicando la huida como forma de evadir la proletarización forzosa, reinciden en sus prácticas transgresoras y libertinas al interior de sus ámbitos de sociabilización y si bien no rechazan explícitamente el discurso moralizador, prácticamente en ningún caso se hacen cargo del mismo. Pero además, y en no pocas ocasiones, los sectores populares reaccionan violentamente contra las compulsiones elitarias. El motín urbano, el levantamiento minero y el bandolerismo rural, se convirtieron en manifestaciones recurrentes de la rebeldía popular frente a las presiones del sistema de dominación (Goicovic, 2003, 2002, 2000a, 2000b y 1997).

\section{VIOLENCIA Y SOCIEDAD}

Como señalamos previamente, los estudios históricos sobre violencia para el caso chileno son escasos. La carencia historiográfica es aún más evidente para un período clave en la historia social de nuestro país: 1850-1912. Mientras los clásicos de la historia social — pioneros y contemporáneos - coinciden en que la fase antes aludida es señera en transformaciones profundas en la sociedad y en la estructura económica de Chile, los aspectos más controversiales de dicha transición han quedado prácticamente relegados a las nota a pie de página $\mathrm{y}$, cuando mucho, a algunos estudios específicos referidos a coyunturas movimientales que tienden a explicarse por sí mismas. La carencia fundamental, en consecuencia, se expresa en la inexistencia de estudios en profundidad para el conjunto de los fenómenos sociales involucrados en lo que denominamos la protesta social popular. Es decir, un enfoque analítico que se haga cargo - a partir de sus especificidades- del motín urbano popular, del levantamiento minero y del bandolerismo rural. 
Los déficits que presenta este nivel de análisis se deben, en parte, a que los estudios históricos atingentes a los sectores populares tienden a considerarlos como compartimientos sociales separados: mineros, campesinos, pobres urbanos, sin hacerse cargo de las matrices culturales comunes que identifican el ethos social del sujeto popular. En nuestra perspectiva analítica los actores social-populares de fines del siglo XIX y comienzos del siglo XX comparten ámbitos de constitución de identidad y mecanismos de sociabilidad, que nos permiten establecer rasgos comunes en sus formas de ser social. Uno de los aspectos clave a considerar en esta óptica analítica es precisamente la conducta violenta que ejercen estos sectores populares respecto del Estado y las élites dominantes (Drapkin, 1958:48-53). ${ }^{2}$ En relación con esta temática la historiografía social ha sido particularmente huidiza. Mientras el marxismo clásico tiende a relevar las expresiones reactivas del Estado y de las clases dominantes sobre los actores populares movilizados (Jobet, 1955; Ramírez Necochea, 1956; Barría, 1972), la historia social contemporánea (Devés, 1989; Garcés, 1980; Salazar, 1985), enfatiza respecto de los rasgos específicos que concurren a constituir al sujeto social en actor colectivo. En ambos enfoques la lógica discursiva nos presenta a un actor social replegado sobre sus entornos comunitarios; en una - la primera - como producto de la intervención represiva que golpea y desarticula; en la otra - la segun$\mathrm{da}-$, como consecuencia lógica de una práctica social que privilegia lo comunitario por sobre lo estatal. En ambos discursos, además, el sujeto social-popular es develado como objeto de compulsiones, castigos y sanciones, recreándose, de esta manera, una historia del martirologio que tan profundamente ha encarnado en el discurso y en la práctica política de la izquierda chilena. Pero ¿fue efectivamente ésta la conducta asumida por los sectores populares en Chile?

En nuestra opinión los sectores populares intervinieron recurrentemente de manera violenta en el escenario social del período en estudio. La violencia por ellos desplegada pone de manifiesto que sus formas de relación con el Estado y con las élites dominantes estuvieron permanentemente conflictuadas $\mathrm{y}$, en ese contexto, la expresión más radical de resistencia cultural fue el levantamiento social. ${ }^{3}$ Las

2 La violencia entendida como la transformación cultural del instinto de agresión, se encuentra desarrollada en Sanmartín, 2002.

3 La representación social de los antagonismos colectivos se encuentra claramente desarrollada en Beck, 2003. 
características específicas de esta manifestación violenta corresponde a tres fenómenos clásicos: el motín urbano, el levantamiento minero y el bandolerismo rural. ${ }^{4}$

El motín urbano ha sido tratado desde ópticas diferentes, pero con similar rigor intelectual por Izquierdo (1976) y por Grez (2000 y 1999). El primero lo asocia a las condiciones materiales de vida de los sectores populares y a la coyuntura crítica de subsistencia del año 1905 , mientras que el segundo percibe los movimientos sociales de fin de siglo en el marco de la constitución del movimiento político moderno. Siendo probablemente los estudios más interesantes respecto de este tópico, ambos adolecen de la mirada de larga duración que permite dimensionar de manera más rigurosa estos movimientos. Un enfoque holístico de este fenómeno social nos permitiría reconocer - siguiendo a Pérez Ledesma (1997) - que la formación de los sectores populares y su intervenciones sociales constituyen una creación cultural. Por su parte, los estudios de Romero (1997) y De Ramón (1985), si bien no asumen el tópico de la revuelta popular como un objeto específico de estudio, sí nos permiten aproximarnos a ella a través de las formas en que se organiza y ocupa el espacio urbano. De la misma manera el trabajo de Valencia (1999), releva la importancia de los espacios de sociabilización popular como instancias de construcción de lealtades y de articulación primaria.

De acuerdo con Rodríguez (1995) el espacio privilegiado para el despliegue de la violencia social urbana era la calle. La calle era el escenario en el cual el poder organizaba y vigilaba la sociedad; en ella se representan la suntuosidad y el simbolismo del poder. Pero la calle, también, era un espacio de libertad, de molestias y reclamos; es también un espacio abierto e incontrolado en el cual opera la delincuencia organizada. En ella se expresan con violencia las contradicciones y conflictos que afectan a las clases subalternas.

Por su parte los levantamientos mineros en los distritos salitreros han sido tratados en una amplia bibliografía por Pinto (especialmente, 1998). En ellos Pinto, establece con claridad que las revueltas peonales de fines del siglo XIX se encuentran en la lógica de resistencia a la proletarización que llevaron a cabo los trabajadores inmigrados al

4 De acuerdo con Elias (1998:85), estas expresiones de violencia social responden o son consecuencia de las relaciones de discriminación, exclusión y de autopercepción de superioridad o subordinación, construidas a partir de los grados de cohesión, identificación colectiva y mancomunidad de normas que un grupo se da a sí mismo. 
norte. Ello, claro, en el contexto de un proceso lento, pero inexorable, de incorporación a las relaciones sociales de producción capitalistas. Por su parte González (1991), aborda la misma problemática, pero centrando el análisis en las manifestaciones de resistencia cultural desplegadas por trabajadores y grupos étnicos.

Por último, el bandolerismo rural cuenta con dos excelentes trabajos. En el estudio de Valenzuela (1991), se analiza en profundidad el bandolerismo social en la zona central de Chile, durante la segunda mitad del siglo XIX. En este trabajo Valenzuela, siguiendo el modelo de Hobsbawm, da cuenta de la intensidad del fenómeno del bandolerismo en un contexto de agudización de los conflictos sociales por la tierra y como una estrategia de subsistencia con altos niveles de legitimación entre los sectores populares. Mirado desde esta perspectiva habría que relativizar los argumentos de Bengoa, en cuanto a que el bandidismo postindependencia fue la única insurrección masiva de campesinos habida en el país (Bengoa, 1988). Por su parte el estudio de Contador (1998), aborda la constitución de amplias masas de campesinos levantados en armas en la zona sur de Chile, en el marco de las expoliaciones económicas y de las levas forzosas de campesinos, durante y tras el proceso de independencia.

Estos aspectos nos permiten concluir, siguiendo a Bazan (1995), que cada grupo social, mediante mecanismos de socialización, impone a todos sus integrantes unos valores, unas creencias y unos símbolos, de tal forma que se produce en ellos una nivelación y uniformidad de conductas; es decir, participan de un modelo conductual de conformidad o normalidad. El estudio del mundo social y en particular de la violencia social, nos pone de manifiesto hasta que punto los valores culturales han sido asimilados, o si se ha optado por el rechazo de los mismos.

Nos parece interesante destacar, acogiendo las propuestas metodológicas de Álvarez Junco (1995), que el estudio de los movimientos sociales entendidos como los estudios de la clase obrera organizada o de sus antecedentes, siendo una historia necesaria, es una historia que requiere ser contrastada con el estudio de aquellos sectores sociales - de matriz popular - que no responden al análisis clásico de las clases subordinadas. Un aspecto básico a considerar es que los enfrentamientos sociales, particularmente en las sociedades preindustriales, tienden a poner al descubierto la composición heterogénea de los movimientos sociales y la multiplicidad de fenómenos que detonan los conflictos. Los fenómenos de protesta social, permiten relevar cosas 
que permanecen latentes y que explosan en momentos de ruptura, exponiendo todas las características de los problemas que atraviesan a la sociedad. En consecuencia debemos analizar el fenómeno de crisis en el contexto de la dinámica de la sociedad. Los fenómenos de violencia son parte de la dinámica más amplia del movimiento de la sociedad, de manera que al estudiarlos debemos tener en cuenta este antecedente (Hobsbawm, 1981).

\section{LA DINÁMICA HISTÓRICA DE LA VIOLENCIA EN CHILE}

Durante el siglo XVIII la expansión de las actividades económicas - especialmente cupríferas y trigueras - y el subsecuente crecimiento de la población, coinciden en el tiempo con el impulso dado por la Corona española a la política de fundación de villas en Indias. De esta manera, durante la centuria del setecientos se llevaron a cabo 24 proyectos de creación de ciudades al norte y al sur de la ciudad de Santiago de Chile (Lorenzo, 1983). El objetivo fundamental de la política borbónica era intervenir en la conformación del espacio urbano y social, racionalizándolo y regulando a sus ocupantes. Las nuevas villas - San Rafael de Rozas, Santa Ana de Briviesca, San Felipe del Real, entre otras-, se convirtieron, entonces, en la punta de lanza de la política borbónica, la cual pretendía reponer la autoridad estatal al interior de una sociedad —eminentemente rural—, férreamente controlada por la oligarquía latifundaria (Salinas y Goicovic, 2000).

Sobre esta base conceptual y política descansaban los cuatro ejes del proyecto urbano: civilizar a la población - concentrando a los vagabundos, mendigos, viciosos, libertinos y delincuentes-, recurriendo a instrumentos coactivos — bandos de buen gobierno- y al hipotético influjo civilizador de la vida en la ciudad; facilitar el ejercicio de la acción pastoral de la Iglesia y permitir mejores condiciones de subsistencia al cura párroco; fortalecer la capacidad de defensa del reino frente a eventuales levantamientos indígenas; y desarrollar el potencial económico de las ciudades, concediendo privilegios y ventajas tributarias a los vecinos e incentivando el desarrollo de la actividad industrial —obrajes- (Lorenzo, 1987).

Pero el objetivo de establecer villas habitadas por pequeños propietarios-productores, a partir de la subdivisión de la gran propiedad - siguiendo el modelo europeo-, fracasó. Sólo se logró entregar retazos de tierras comunales o expropiar las tierras de los pueblos de indios lo que resultó insuficiente. Por otra parte, el proyecto civiliza- 
dor también se vio frustrado, debido a que el poblamiento de las villas correspondió mayoritariamente a labradores y mineros, en general pobres, que edificaron viviendas rústicas e imprimieron al emergente paisaje urbano marcados rasgos de ruralidad.

Las resistencias impuestas por los latifundistas al proceso de fundación de villas en siglo XVIII tiende a atenuarse durante el XIX. Pero ello no devino, automáticamente, en la modernización de los ámbitos de sociabilidad o de las relaciones sociales; éstas, hasta bien avanzado el siglo XX, continuaron explicitando fuertes resabios rurales (Salinas, 1998a). Ciudad y mundo rural eran fracciones de un continuo que estaba conectado, a través del comercio y de las relaciones de sociabilidad, en una relación de intensa dependencia (De Ramón, 1985). Es por ello que la administración de justicia, el control de los desmanes sociales — vagabundaje y bandidaje—, la escolarización y la sujeción de los cuerpos y las almas a los preceptos de la Iglesia, se convirtieron en los objetivos fundamentales de las autoridades urbanas.

El pueblo, particularmente los grupos excluidos y marginados, se constituían en sus propios reductos de vida cotidiana, en los cuales desplegaban sus propias costumbres y formas de vida, en muchos casos asociadas a la vagancia, la trashumancia y el accionar delictual (Bengoa, 1988; Carmagnani, 1963). En general se trataba de sujetos atrevidos e irreverentes que preservaban celosamente su independencia. El carácter de comunidad móvil que identifica a la sociedad chilena decimonónica — producto de los recurrentes desplazamientos de su población-, genera una visión del mundo y de sí misma diferente a la de un grupo social asentado permanentemente. De esta manera, la visión que se construye de quien transgrede el orden establecido - el bandido, el roto alzado - es una visión mágica, mezcla de admiración y temor. Representa, en todo caso, al que ha roto las reglas impuestas por la clase dominante y posee una vida alternativa más libre. Pero estas imágenes construidas socialmente difieren de la praxis real del bandolero, que lejos de ser mágico y heroico es una condición peligrosa; y que además, en la mayoría de los casos, ataca a los de su misma clase (Daitsman, 1990).

En todo caso, el despliegue de una conducta social autónoma por parte de los sectores populares se vio favorecido por el contexto de desorden institucional y por el relajamiento de los mecanismos de control social en la coyuntura desatada por la Guerra de Independencia (Goicovic, 2000b; Contador, 1998). Efectivamente, las movilizaciones y enfrentamientos político-militares del período, relajaron la 
autoridad hacendal y permitieron la organización armada del campesinado - las montoneras-.

Es precisamente en el bandolerismo donde encontramos el origen de la rebeldía y de la protesta popular. El bandolerismo se convierte, por oposición, en una clave de la cultura del sometimiento que se construyó en la sociedad chilena del siglo XIX (cf. los conceptos cultura del sometimiento, Bazan, 1995; y capital cultural, Bourdieu, 1990). Es así como los procesos migratorios campo-ciudad, que comienzan a manifestarse con particular intensidad desde la segunda mitad del siglo XIX, trasladan parte importante de las formas de intervención cultural del mundo agrario hacia las nacientes urbes - especialmente hacia los arrabales suburbanos-y, con ello, acentúan los conflictos sociales explicitados como conductas delictuales y revuelta o motín popular. Se produce de esta manera un doble proceso de transformación en el entorno urbano: por una parte se puede observar la descomposición de la cultura campesino-peonal y la emergencia de una cultura peonal urbana en proceso de proletarización y, por la otra, el trastorno y colapso de la ciudad patricio-colonial y el surgimiento de la moderna ciudad burguesa. Un rol fundamental en este proceso de descomposición de la ciudad patricio-colonial lo van a jugar los ámbitos de sociabilización en los cuales se despliega la cultura popular — pulpería, bodegón, chingana, etc.- y los juegos y diversiones — cancha de carrera, riña de gallos, juegos de naipes - y las festividades religiosas y civiles (Núñez, 1998).

La estabilización de las villas y ciudades desde mediados del siglo XIX estuvo acompañada de un proceso de consolidación de la autoridad pública en la totalidad del territorio nacional. ${ }^{5}$ Ello se enmarca en la ofensiva social, cultural, moral y militar — con fuerte carga físico-institucional-, desplegada por las clases dominantes, el Estado y el aparato ideológico, en torno a reorientar la sociedad popular con-

5 Un aspecto particularmente interesante, muy bien desarrollado en la ciencia política, permite establecer que la violencia constituye un elemento fundante de las relaciones de poder a nivel social. Al respecto Walter señala: «La función de la violencia en el proceso de fundación de derecho es doble, por una parte, la fundación de derecho tiene como fin ese derecho que con la violencia como medio, aspira a implantar. No obstante, el derecho, una vez establecido, no renuncia a la violencia. Lejos de ello, sólo entonces se convierte verdaderamente en fundadora de derecho en el sentido más estricto y directo, porque este derecho no será independiente y libre de toda violencia, sino que será, en nombre del poder, un fin íntima y necesariamente ligado a ella». Walter (1998:40). 
forme a las pautas de la sociedad urbana (Salazar, 1985). Manifestaciones específicas de este fenómeno son los bandos de buen gobierno - que regulaban desde el orden público hasta el trabajo forzadodictados en todas las ciudades emergentes, la organización de milicias y cuerpos militares profesionales a partir de levas forzosas, la dictación del Código Civil de 1844 y la configuración de un Estado autoritario a partir de las normativas de excepción emanadas de la Constitución Política de 1833. Una de las iniciativas más importantes tomadas en torno al control de la actividad delictual fue la implementación del Presidio Ambulante (1836), destinado a disciplinar a la población reclusa de mayor peligrosidad. El sistema en cuestión, originado en un proyecto del ministro Diego Portales, involucraba la reclusión de reos en jaulas de hierro ambulatorias y el sometimiento de los reclusos a trabajos forzados, combinando de esta manera el encierro y la humillación pública (León, 1998). Sólo la habilitación de la Penitenciaría de Santiago, en 1847, como centro de reclusión permanente para los delincuentes vino a transformar el sistema carcelario, imponiendo el encierro por sobre la exposición de los reos (Delgado, 2004).

Por otro lado la expansión de las actividades mineras - especialmente salitreras - en el norte del territorio, a partir de 1865, acentuó los desplazamientos de población y el uso de las villas y ciudades como lugares de asentamiento y tránsito para el peonaje. Emerge de esta manera en el paisaje urbano el rancherio, como densificación y extensión de los cinturones suburbanos. La subdivisión del espacio ocupado se transformó, entonces, en una tendencia. Este proceso fue mucho más intenso en los sectores marginales del primitivo radio urbano, donde se asistió a una verdadera atomización del espacio, ocupado desde el comienzo por pobladores muy pobres y semidesarraigados. La expansión de la ciudad se hizo a costa de las tierras agrícolas inmediatas, por la vía de la compraventa, el arriendo especulativo o la ocupación de hecho. En este proceso - liderado por particulares-, las autoridades administrativas tuvieron una muy poca o escasa injerencia desde el punto de vista de su regulación y control. Las poblaciones populares estaban levantadas en terrenos que pertenecían en todo o en parte a rentistas que las habían comprado o heredado y fueron una combinación de rancherías y conventillos donde los moradores estaban a título de arrendatarios o inquilinos. Se trataba de ranchos de paja, estrechos y pequeños, asentados en una traza irregular. Las edificaciones de adobe se hacían con la tierra del sitio arrendado y la excavación dejaba las viviendas bajo el nivel de la calle, 
exponiéndola regularmente a las inundaciones derivadas de la saturación de las acequias (De Ramón, 1985). Los rancheríos, al expandirse, se unieron entre sí formando extensos arrabales. De esta manera, la práctica acumulativa del patriciado se volvió contra ellos mismos al no ser capaces de contener o encausar urbanísticamente la plebeyización de las ciudades.

El arribo masivo de los sectores populares a la ciudad patricia colonial y su asentamiento precario en las mismas generó deplorables condiciones de vida en los arrabales suburbanos: alimentación deficitaria, altos consumos de alcohol, precariedad y mala conformación de la vivienda, recurrencia de enfermedades y epidemias, que desembocan en una serie de conductas sociales cuestionadas y combatidas por las clases dominantes: desaseo, abandono, violencia, ilegitimidad, hacinamiento, promiscuidad y desorganización familiar (Romero, 1984). Cabe destacar que un segmento importante del peonaje urbano se encontraba sometido a un enganche compulsivo para los trabajos de obras públicas, el servicio doméstico, el ejército o en las cuadrillas de presidiarios. Mientras que otro núcleo del mismo se concentraba en las actividades propias del comercio regatón o minorista. Este tipo de comercio se asentaba en la expansión continua de la ciudad bárbara, y por ende en el mercado fraterno y exclusivo que allí se les presentaba. Inicialmente el comercio regatón fue avalado por los mercaderes urbanos — subastador de abastos-, que se beneficiaban de su institucionalización relativa - pequeñas contribuciones y coimas-, al punto que, hacia 1840, los regatones dominaban las calles de las ciudades más importantes (Salazar, 1991).

El comercio urbano-peonal sobrevivió a las presiones municipales y a los monopolios urbanos de abasto y fue siempre, para el peonaje urbano, un medio de sobrevivencia más flexible y remunerativo que el trabajo asalariado preindustrial. En todo caso no resolvía los problemas estructurales al peonaje, como el desempleo, la miseria o el hacinamiento habitacional. De esta manera las ciudades se convirtieron en polos de atracción para el peonaje porque en ellas encontraban albergue, fraternidad y mercado.

Como señalamos previamente, los desplazamientos de población de la segunda mitad del siglo XIX y el asentamiento de los sectores populares en la periferia urbana de las grandes ciudades y villas hicieron colapsar definitivamente la ciudad colonial. Ello porque la sociedad chilena tradicional - siglos XVIII y primera parte del XIX- si bien era una sociedad escindida - porque se dividía claramente en dos 
clases: patricios y rotos - también era integrada - porque ambos sectores se reconocían como pertenecientes a un mismo ámbito, a un universo común, en el cual podían vivir juntos-. Pero las presiones modernizadoras impuestas por la expansión de la economía y por la transformación de las relaciones de producción en sentido capitalista, segregó definitivamente los ámbitos de sociabilidad. Esto queda de manifiesto en el gradual proceso de erradicación de los sectores populares desde la zona céntrica de las ciudades y su traslado a los extramuros (De Ramón, 1985). Con ello la desintegración de la ciudad colonial se completa y la exclusión modifica sustancialmente las formas de relacionarse entre la élite y los sectores populares, introduciendo, con ello, nuevos criterios de articulación identitarios (cf. Romero, 1987; Elias, 1998).

De esta manera la expansión permanente de ciudades como Santiago de Chile, desde la segunda mitad del siglo XIX en adelante, y el subsecuente desencadenamiento de problemas urbanos y sociales, deviene en el levantamiento de un cerco - el camino de cintura - que separa - en palabras del intendente Benjamín Vicuna Mackenna- la ciudad decente del Cairo infecto (Romero, 1989).

La sociedad popular que se recrea y construye al interior de la ciudad plebeya, despliega formas y mecanismos de sociabilidad que amparan y encubren - solidariamente - las conductas transgresoras de sus integrantes: actuar escandaloso, subversiones afectivas, concurrencia o regencia de espacios de diversión y expropiación de bienes de la élite dominante. Pero, de la misma manera, es capaz de establecer formas de control social que resguardan aquellos principios, valores o tradiciones que el grupo social acepta como significantes e inviolables. Es posible reconocer los instrumentos del control social en el mismo quehacer cotidiano de la comunidad: la puerta y la ventana no sólo marcan el límite entre el ámbito doméstico y el comunitario, también se convierten en atalayas desde las cuales se observa la conducta de los demás. A su vez, las voces comunitarias - el rumor-se convierten en instrumentos de denuncia o inhibición de determinadas conductas evaluadas como transgresoras (Salinas, 1998b). Por su parte la posición social de los sujetos en el barrio instituye ciertas jerarquías locales que condicionan la articulación de redes clientelares o de subordinación (cf. Imizcoz, 1995 y 1996).

Las comunidades urbano populares construyen redes de sociabilidad en las cuales se combinan permanentemente conflictos y solidaridades, de tal manera que la pasión, el odio, el amor, la amistad, los 
intereses, se entrecruzaban permanentemente exacerbando una conflictividad que se manifiesta a flor de piel. De esta manera, las relaciones asientan un tipo de sociabilidad que canaliza y controla tensiones potenciales que se suceden cotidianamente. Así, involucrarse y participar en las redes de relaciones callejeras se convierte en un principio organizativo de la comunidad, capaz de resguardar o eventualmente restablecer el equilibrio interno de la sociedad. La información que allí se transaba en los circuitos de la cotidianeidad constituía la referencia válida y verdadera del grado de compromiso del individuo con la escala de valores éticos socialmente reconocidos y compartidos o, a la inversa, con el grado de marginalidad en que se sitúa quien contraviene la norma (Salinas, 1996). En este contexto la violencia fue una constante en las relaciones interpersonales de las sociedades precapitalistas. Ello se explica por la existencia de una agresividad marcada por la propia dinámica de las relaciones sociales establecidas a nivel de calle, de barrio, profesión o de gobierno político (cf. Sodré, 2001; Zulaika, 1993).

La historia de la violencia y de la criminalidad, por lo tanto, es una historia de las relaciones entre el poder, la sociedad y los sujetos a través de la mediación del derecho, como norma y como práctica (Moreno y Bertran, 1995). Es precisamente en el complejo sistema de los valores y sus contrarios donde radica el origen de la violencia individual e institucional, las que se proyectan de tres maneras: contra los cuerpos - aborto, tormento, riña, duelo, violación, rapto, suicidio, homicidio, asesinato, ejecución de la pena de muerte- contra la propiedad - hurtos, asaltos, robos, falsificaciones, fraudes, corrupcióny contra el pensamiento - la más difusa de todas: censura, índice de libros prohibidos, expurgatorios- (Herzog, 1995; Rodríguez, 1995).

Los espacios o ámbitos en los cuales se despliega la violencia son los propios del quehacer cotidiano. La calle, en cuanto lugar de exposición de las diferentes formas de interrelación social y como escenario en el cual el poder organiza, articula y vigila - sobre todo de noche-, las conductas de los sujetos. En las zonas rurales el teatro de la violencia se focaliza en las orillas frecuentadas de los ríos y en los caminos abiertos. La cárcel, concebida como espacio especializado en la tortura, la reyerta, el juego y la corrupción. Y, por último, la Iglesia, en cuanto reducto de represión de las desviaciones ideológicas.

En las villas y ciudades chilenas de la segunda mitad del siglo XIX, las condiciones de vida y de seguridad de la población eran muy precarias. La violencia era un fenómeno recurrente y el temor a las 
acciones delictuales o violentas constituía una preocupación permanente para las autoridades y las clases dominantes. Los arrabales y las poblaciones periféricas de las ciudades eran percibidas como refugio y guarida de todo tipo de bandoleros, transgresores, prostitutas y mal avenidos. La difícil convivencia vecinal, la alarma y el terror permanente, la ebriedad y el crimen eran, en estos sectores urbanos, el pan de cada día (De Ramón, 1985). Parte importante de los conflictos que se generan en los barrios populares se originan en los lugares de recreación que la periferia semirural ofrece a la ciudad. A ellos concurrían masivamente los sujetos populares, especialmente en la temporada de primavera y verano. Las entretenciones y competencias que se llevaban a cabo en estos ámbitos eran acompañadas de una considerable ingesta de alcohol, lo cual las convertía en situaciones imprudentes, temerarias e incluso violentas. Eran particularmente las masas de trabajadores cesantes o subempleados quienes se constituían en un peligro para la paz. En estos ámbitos de repliegue festivo de los sujetos populares se producía el reclutamiento de quienes habrían de incorporarse a las protestas políticas de la élite. Pero la intervención del bajo pueblo en dichos eventos discurría por una senda que se alejaba radicalmente de los objetivos y conductas políticas de las clases dominantes.

En toda situación de conflicto social, los aspectos que más preocupaban a la élite dominante y a sus medios de comunicación social, la constituían los sectores populares y sus formas de intervención violenta contra la propiedad pública y privada y contra el aparato de seguridad del Estado - la policía y el ejército-. Era dicha conducta violenta la que amagaba la estabilidad social y proyectaba situaciones de desorden institucional que era necesario contener. La presencia de las turbas populares en el centro cívico, amagando los locales comerciales y los recintos que cobijaban al poder, o las bandas de campesinos armados que saqueaban las propiedades de la oligarquía hacendal, comenzaron a transformarse en un fenómeno complejo, difícil de resolver para la élite.

El amotinamiento urbano tenía como rasgo característico el despliegue de la poblada en el centro cívico de la ciudad. La muchedumbre reunida cargaba rápidamente contra los establecimientos comerciales, a objeto de saquearlos y obtener recursos de subsistencia. Simultáneamente se actuaba con inusitada violencia contra los medios de transporte público (tranvías), contra el alumbrado y contra los edificios públicos y privados. La presencia de la policía o de las tropas de 
línea regularmente enardecía los ánimos de los amotinados, los que cargaban desordenadamente contra ella agrediéndola con objetos contundentes (piedras y palos) y en algunas ocasiones con armas corto-punzantes (cuchillos, estoques, etc.). La respuesta policial y militar frente a este tipo de acontecimientos era tan dura como la misma protesta. La fuerza pública entraba sobre los amotinados con cargas de caballería y con descargas de fusilería, a objeto de reducir a los más violentos y dispersar a la masa revoltosa (Goicovic, 2002).

La presencia violenta de los sectores populares en la ciudad patricia llenaba de desconcierto a los sectores dominantes. ¿Quiénes eran estos sujetos sociales que se atrevían a enfrentar violentamente al Estado y a su aparato represivo?, ¿qué oscuras motivaciones los llevaban a subvertir el orden cívico que las autoridades se empeñaban denodadamente en mantener? Para la prensa la respuesta era clara. Se trataba del populacho, de la multitud mal encarada, de los grupos de harapientos, de los hombres de mirada torva, que se entregaban periódicamente a la destrucción torpe e incalificable.

El discurso oficial sobre la protesta popular, hasta bien avanzada la segunda mitad del siglo XIX, continuó negando la existencia de problemas estructurales como precipitantes del accionar violento de las masas. La mayoría de los tribunos públicos del período consideraban que la masa de harapientos actuaba violentamente como consecuencia de sus instintos brutales. ${ }^{6} \mathrm{El}$ discurso regenerativo involucraba sólo a un grupo reducido de teóricos sociales, conscientes de los peligros que entrañaba la masa proletaria. ${ }^{7}$ Para estos últimos, la pobreza, el hambre y la ignorancia eran el motor de la revuelta popular. Frente a esta situación aparecía como urgente desplegar iniciativas tendientes a la regeneración moral del pueblo y, para ello, se podía contar con los artesanos; es decir, con el segmento ilustrado de la clase trabajadora que se negaba a participar del motín (Grez, 1997). El artesano debía convertirse en el contrapeso que debía oponerse a la torpeza de las últimas capas sociales y ahí debía encaminarse el esfuerzo común.

6 El control de los medios de comunicación y de los espacios de formación (escuela), por parte del Estado y de las élites oligárquicas, permite construir una imagen satanizada del bajo pueblo. Al respecto ver Hedges, 2002.

7 El positivismo y su noción de progreso se encuentra a la base de la reflexión teórica que acompaña al higienismo y a la criminología. Ambas se constituyeron, a fines del siglo XIX, en los instrumentos de diagnóstico y planificación respecto del mundo popular. Ver Del Olmo, 1999. 
Pero también se hacía necesario redoblar las medidas de control social. Vigilar de manera permanente los nichos urbanos en los cuales se recluían los pobres a objeto de contener y reprimir in situ los eventuales desbordes del arrabal. No llama la atención, por lo tanto, que tras los motines, algunas partidas de policía recorrieran por la noche los barrios periféricos de la población, como Chuchunco, la Alameda de los Padres, el Matadero y la Acequia Grande con el objeto de mantener la tranquilidad, si a alguien se le ocurriera alterarla.

Pero los motines urbanos, los levantamientos mineros y el bandolerismo rural, no sólo desencadenaron la reacción represiva del Estado y de las élites dominantes, también operaron - posteriormente- como facilitadores en la elaboración del discurso de la cuestión social. En este proceso las problemáticas del mundo popular comenzaron a ser abordadas gradual y simultáneamente, desde una óptica represiva e integradora. Las manifestaciones más agudas de la protesta popular recibió cotidianamente el castigo ejemplarizador del Estado, pero los sectores que renunciando a la tendencia levantisca buscaron y encontraron un espacio institucional a sus demandas, se convirtieron rápidamente en los interlocutores legitimados de las clases populares ante el Estado (Grez, 2001). De esta manera los sectores populares transitaron, entre fines del siglo XIX y comienzos del siglo XX, desde la lógica del enfrentamiento a la lógica de la integración subordinada.

Parte importante de los acontecimientos posteriores protagonizados por el movimiento popular en Chile hunden sus raíces más profundas en este proceso de transición que situamos como objeto de estudio. De hecho colocamos como hito de cierre de este proyecto el año 1912, fecha en la cual se funda el Partido Obrero Socialista (POS), momento histórico en el cual, a nuestro juicio, el movimiento popular deriva definitivamente hacia formas de intervención social intrasistémicas. Esto significa que las lógicas organizacionales impuestas por las élites ilustradas del movimiento popular encapsularon las dinámicas movimientales y violentas con las cuales se instalaba el movimiento popular en el escenario social decimonónico.

La punta de lanza en este proceso la proporcionó el movimiento urbano artesanal. Considerado por la élite dominante como el sector social más ilustrado y cobijando en su seno políticas, programas y disposiciones específicas de integración social, el movimiento urbano artesanal tendió el puente organizacional al proceso de desarme cultural de las masas peonales levantiscas. La conclusión de dicho proceso la aportaron simultáneamente el POS y la Federación Obrera de Chile 
(FOCH), al sistematizar programáticamente las formas premodernas de violencia social desplegadas por los sujetos populares. A partir de este momento $-\mathrm{y}$ hasta bien avanzado el siglo $\mathrm{XX}$ - la violencia se convierte en discurso, pero deja de ser práctica social.

OSORNO (CHILE), NOVIEMBRE 2004

RECIBIDO: NOVIEMBRE 2004

ACEPTADO: DICIEMBRE 2004

\section{REFERENCIAS BIBLIOGRÁFICAS}

Aguirre, Carlos (1993): Agentes de su propia libertad. Los esclavos de Lima y la desintegración de la esclavitud, 1821-1854. Lima: Pontificia Universidad Católica del Perú.

Aguirre, Carlos y Charles Walker (editores) (1990): Bandoleros, abigeos y montoneros. Criminalidad y violencia en el Perú, siglos XVIII-XX. Lima: Instituto de Apoyo Agrario.

Álvarez JunCO, José (1995): «Aportaciones recientes de las ciencias sociales al estudio de los movimientos sociales». En Historia a debate, Tomo III, Otros enfoques. Santiago de Compostela: Universidad de Santiago de Compostela.

AnteZAna, Luis (1994): Masacres y levantamientos campesinos en Bolivia. La Paz: Editorial Juventud.

— (1999): La guerra entre La Paz y Chuquisaca (1899). La Paz: Ilustre Municipalidad de La Paz.

Aston, T. H. y C. H. E. PhiLPIN (editores) (1988): El debate Brenner. Estructura de clases agraria y desarrollo económico en la Europa preindustrial. Crítica: Barcelona.

Barría Serón, Jorge (1972): El movimiento obrero en Chile. Síntesis históricosocial. Santiago: Ediciones Universidad Técnica del Estado.

Barros Arana, Diego (1884-1902): Historia jeneral de Chile, 16 volúmenes. Santiago de Chile: Rafael Jover Editor.

BAUER, ARnOlD (1970): «Expansión económica en una sociedad tradicional: Chile central en el siglo XIX». Historia $\mathrm{N}^{\circ}$ 9. Santiago: PUC.

BAyer, Osvaldo (2002): La patagonia rebelde. Buenos Aires: Planeta.

- (2003): Los anarquistas expropiadores y otros ensayos. Buenos Aires: Planeta.

BAZAN, IÑAKI (1995): «La historia social de las mentalidades y la criminalidad». En Carlos Barros (editor): Historia debate. Retorno del sujeto, Vol. 2. Santiago de Compostela: Universidad de Santiago de Compostela.

Beck, AARon T. (2003): Prisioneros del odio. Barcelona: Editorial Paidós.

BengoA, José (1987): Historia del pueblo mapuche. Siglo XIX y XX. Santiago: Ediciones SUR.

(1988): Historia social de la agricultura chilena. El poder y la subordinación, Tomo I. Santiago: Ediciones SUR. 
CARMagnani, Marcello (1963): El salariado minero en Chile colonial. Su desarrollo en una sociedad provincial. El Norte Chico, 1690-1800. Santiago: Universidad de Chile, Centro de Historia Colonial, Editorial Universitaria.

- (1998): Desarrollo industrial y subdesarrollo económico. El caso chileno (1860-1920). Santiago: DIBAM.

Contador, Ana María (1998): Los Pincheira. Un caso de bandidaje social. Chile, 1817-1832. Santiago: Bravo y Allende Editores.

Chiavenato, Julio José (2002): As lutas do povo brasileiro. Do descubrimiento a Canudos. São Paulo: Editora Moderna.

Daitsman, Andy (1990): «Bandolerismo: mito y sociedad. Algunos apuntes teóricos». Proposiciones N¹9. Santiago: Ediciones SUR.

DE RAMÓN FOLCH, ARMANDO (1985): «Estudio de una periferia urbana: Santiago de Chile, 1850-1900». Historia $\mathrm{N}^{\circ} 20$. Santiago: PUC.

Del Olmo, Rosa (1999): América Latina y su criminología. México: Siglo XXI.

Del Valle, María Eugenia (1990): Historia de la rebelión de Tupac Catari, 17811782. La Paz: Editorial Don Bosco.

Delgado Valdivia, Felipe (2004): «La racionalización del castigo en Chile. De la forma a los contenidos en la práctica punitiva (1843-1874)». Memoria de Graduación. Santiago: Departamento de Historia, USACH.

DEVÉs, EdUARDo (1989): Los que van a morir te saludan. Historia de una masacre. Escuela Santa María, Iquique, 1907. Santiago: Ediciones Documentas.

DobB, MAURICE (1979): Estudios sobre el desarrollo del capitalismo. Madrid: Siglo XXI.

Drapkin Senderey, ISRAel (1958): «Prensa y criminalidad». Anales de la Universidad de Chile $\mathrm{N}^{\circ} 111$. Santiago: Ediciones Universidad de Chile.

ECKSTEIN, SusAn (coordinadora) (2001): Poder y protesta popular. Movimientos sociales latinoamericanos. México: Siglo XXI.

EliAs, NORBERT (1998): «Ensayo teórico sobre las relaciones entre establecidos y marginales». En La civilización de los padres y otros ensayos. Bogotá: Editorial Norma.

Encina, Francisco Antonio (1983-1984): Historia de Chile. Desde la prehistoria hasta 1891, 37 Volúmenes. Santiago: Editorial Ercilla.

Eyzaguirre, Jaime (1965): Historia constitucional de Chile. Santiago: Editorial Universitaria.

Flores Galindo, Alberto (1983): Los mineros de la Cerro de Pasco, 1900-1930. Lima: Pontificia Universidad Católica del Perú.

Fonseca JúNIOR, EdUARdo (2003): Zumbi dos Palmares. Herói negro da nova conciencia nacional. São Paulo: Editora Atheneu.

FORSTER, ROBERT y JACK GREENE, (compiladores) (1984): Revoluciones y rebeliones de la Europa moderna. Madrid: Alianza.

GARCÉs DuRÁN, MARIO (1991): Crisis social y motines populares en el 1900. Santiago: Ediciones Documentas.

- (1980): «El modelo de mundo propuesto por el mancomunalismo». En La visión del mundo del movimiento mancomunal en el norte salitrero entre 1901 y 1907. Santiago: Academia de Humanismo Cristiano.

García de León, ANTONio (1994): Resistencia y utopía. Memorial de agravios y crónica de revueltas y profecías acaecidas en la Provincia de Chiapas durante los últimos quinientos años de su historia. México: ERA. 
Godio, Julio (2000): Historia del movimiento obrero argentino, 2 Vols. Buenos Aires: Ediciones Corregidor.

GoICOVIC DonOSO, IGOR (1997): «Surco de sangre, semilla de redención. La revuelta campesina de La Tranquilla (1923)». Valles. Revista de Estudios Regionales $\mathrm{N}^{\circ} 3$. La Ligua: Museo de La Ligua.

_ (2000a): «Del control social a la política social. La conflictiva relación entre los jóvenes populares y el Estado en la historia de Chile». Última Década $\mathrm{N}^{\circ} 12$. Viña del Mar: Ediciones CIDPA.

_ (2000b): «Conflictividad social y violencia colectiva en Chile tradicional. El levantamiento indígena y popular de Chalinga (1818)». Revista de Historia Social y de las Mentalidades $\mathrm{N}^{\circ} 4$. Santiago: Departamento de Historia, USACH.

- (2002): «La insurrección del arrabal. Espacio urbano y violencia colectiva. Santiago de Chile, 1878». Revista de Historia Social y de las Mentalidades N ${ }^{\circ} 6$. Santiago: Departamento de Historia, USACH.

- (2003): «El discurso de la violencia en el movimiento anarquista chileno (18901910)». Revista de Historia Social y de las Mentalidades N7. Santiago: Departamento de Historia, USACH.

GONZÁlez, SERGio (1991): Hombres y mujeres de la pampa. Iquique: TER.

Grez Toso, Sergio (1997): De la 'regeneración del pueblo' a la huelga general. Génesis y evolución histórica del movimiento popular en Chile (1810-1890). Santiago: DIBAM.

_ (1999): «Una mirada al movimiento popular desde dos asonadas callejeras (Santiago, 1888-1905)». Cuadernos de Historia N¹9. Santiago: Universidad de Chile.

_ (2000): «Transición en las formas de lucha: motines peonales y huelgas obreras en Chile (1891-1907)». Historia No33. Santiago: PUC.

_ (2001): «La guerra preventiva. Escuela Santa María de Iquique. Las razones del poder». Mapocho $\mathrm{N}^{\circ} 50$. Santiago: DIBAM.

HARRIS, GILBERTO (1997): «Tribulaciones de los emigrados chilenos en Perú, Bolivia y Argentina durante el siglo XIX». En CARMEN NORAMBUENA (editora): ¿Faltan o sobran brazos? Migraciones internas y fronterizas (1850-1930). Santiago: Editorial Universidad de Santiago.

Hedges, Chris (2002): La guerra es la fuerza que nos da sentido. Madrid: Editorial Síntesis.

Heise, Julio (1974 y 1982): Historia de Chile. El periodo parlamentario (18611925), 2 tomos. Santiago: Editorial Andrés Bello.

Herzog, TAmAR (1995): La administración como un fenómeno social: la justicia penal de la ciudad de Quito (1650-1750). Madrid: Centro de Estudios Constitucionales.

HobsBawm, ERIC (1981): «De la historia social a la historia de la sociedad». Eco, Tomo XLIV/6, N²40: Bogotá.

— (1998): Industria e imperio. Una historia económica de Gran Bretaña desde 1750. Buenos Aires: Planeta-Ariel.

_ (1999a): Historia del siglo XX. Barcelona: Crítica.

— (1999b): Gente poco corriente. Resistencia, rebelión y jazz. Barcelona: Crítica. (2000): Revolucionarios. Barcelona: Crítica.

- (2001a): La era del imperio, 1875-1914. Barcelona: Crítica.

_ (2001b): La era del capital, 1848-1875. Barcelona: Crítica. 
- (2001c): La era de la revolución, 1789-1848. Barcelona: Crítica.

— (2001d): Rebeldes primitivos. Estudios sobre las formas arcaicas de los movimientos sociales en los siglos XIX Y XX. Barcelona: Crítica.

- (2001e): Bandidos. Barcelona: Crítica.

- (2002): Naciones y nacionalismos desde 1780. Barcelona: Crítica.

Husson, PATRICK (1992): De la guerra a la rebelión. Huanta, siglo XIX. Cusco: Centro de Estudios Regionales Andinos «Bartolomé de Las Casas».

Illanes, María ANGÉliCA (1990): «Azote, salario y ley. Disciplinamiento de la mano de obra en la minería de Atacama». Proposiciones No19. Santiago: Ediciones SUR.

IMIZCOZ, José MARÍA (1995): «Actores sociales y redes de relaciones en las sociedades del Antiguo Régimen. Propuesta de análisis en historia social y política». En Carlos Barros (editor): Historia a debate. Retorno del sujeto, Vol. 2. Santiago de Compostela: Universidad de Santiago de Compostela.

_ (1996): «Comunidad, red social y élites. Un análisis de la vertebración social en el Antiguo Régimen». En José María Imizcoz Beunza (director): Élites, poder y red social. Las élites del País Vasco y Navarra en la Edad Moderna. (Estado de la cuestión y perspectivas). Bilbao: Servicio Editorial Universidad del País Vasco.

IZQUiERdo FernÁndeZ, GonZALO (1976): «Octubre de 1905. Un episodio en la historia social chilena». Historia $\mathrm{N}^{\circ} 13$. Santiago: PUC.

JoBet, Julio CÉSAR (1955): Ensayo crítico del desarrollo económico-social de Chile. Santiago: Editorial Universitaria.

Kapsoli, Wilfredo (1987): Los movimientos campesinos en el Perú. Lima: Ediciones Atusparia.

KAY, Cristobal (1992): "The development of the hacienda system». En PATRICIO SiLVA y CRISTOBAL KAY: Development and social change in the chilean countryside. From the pre-land reform period to the democratic transition. Amsterdam: CEDLA.

LAcoste, PABlo (2000): El ferrocarril trasandino, 1872-1984. Santiago: DIBAM.

LEÓN LEÓN, MARCO ANTONIO (1998): «Entre el espectáculo y el escarmiento: el presidio ambulante en Chile (1836-1847)». Historia $\mathrm{N}^{\circ} 31$. Santiago: PUC.

Lorenzo, SANTiago (1983): Origen de las ciudades chilenas. Las fundaciones del siglo XVIII. Santiago: Editorial Andrés Bello.

_ (1987): «Concepto y funciones de las villas chilenas del siglo XVIII». Historia $\mathrm{N}^{\circ} 22$. Santiago: PUC.

MAYER, ARno (1984): Las persistencias del Antiguo Régimen. Europa hasta la Gran Guerra. Madrid: Alianza.

MOORE, BARRINGTON (1979): Injustice: the social bases of obedience and revolt. New York: M. E. Sharpe.

MORENO, DORIS y J. L. BERTRÁN (1995): «Justicia criminal y criminalidad en la Cataluña moderna». En CARLoS BARRos (editor): Historia a debate. Retorno del sujeto, Vol. 2. Santiago de Compostela: Universidad de Santiago de Compostela.

MourA, Clovis (1988): Rebelioes da senzala: quilombos, insurreiçoes, guerrilhas, Porto Alegre: Mercado Aberto.

NúÑEZ PINTO, JORGE (1998): «Versos por rebeldía. La protesta social en la poesía popular (Siglos XIX y XX». Mapocho Nº43. Santiago: DIBAM. 
O'Phelan, Scarlet (1988): Un siglo de rebeliones anticoloniales. Perú y Bolivia 1700-1783. Cuzco: Centro de Estudios Regionales Andinos «Bartolomé de Las Casas».

_ (1995): La gran rebelión en Los Andes. De Tupac Amaru a Tupac Catari. Cuzco: Centro de Estudios Regionales Andinos «Bartolomé de Las Casas».

ORTEGA, LuIS (1988): «Acerca de los orígenes de la industrialización chilena, 18601879». Nueva Historia $\mathrm{N}^{\mathrm{2}}$ 2. Londres: Asociación de Historiadores Chilenos en Londres.

Ortega, Luis y Julio Pinto (1990): Expansión minera y desarrollo industrial: un caso de crecimiento asociado (Chile, 1850-1914). Santiago: USACH.

Pereda Torres, Rolando (1982): Historia de las luchas sociales del movimiento obrero en el Perú republicano 1858-1917. Lima: Editorial Imprenta Sudamérica.

PÉREZ Ledesma, MANUEL (1997): «La formación de la clase obrera: una creación cultural». En RAFAel CRUZ y MANUEl PÉREz Ledesma (editores): Cultura y movilización en la España contemporánea. Madrid: Alianza.

Pinto Vallejos, Julio (1998): Trabajos y rebeldía en la pampa salitrera. El ciclo del salitre y la reconfiguración de las identidades populares (1850-1900). Santiago: USACH.

PORTER, ROY y Mikulás TeICH (editores) (1990): La revolución en la historia. Barcelona: Crítica.

Ramírez NeCOCHeA, HernÁN (1956): Historia del movimiento obrero en Chile. Antecedentes siglo XIX. Santiago: Austral.

Ramos Zambrano, Augusto (1990): Tormenta altiplánica. Rebeliones indígenas de la provincia de Lampa-Puno, 1920-1924. Lima: Talleres Gráfica Espinal.

Reina, Leticia (1988): Las rebeliones campesinas en México (1819-1906). México: Siglo XXI.

ReIS, JoAo José (1995): Slave rebellion in Brazil. The muslim uprising of 1835 in Bahía. Baltimore: Johns Hopskins University Press.

RodRíGUEZ, ÁNGel (1995): «La historia de la violencia: espacios y formas en los siglos XVI y XVII». En CARLOS BARROS (editor): Historia a debate. Retorno del sujeto, Vol. 2. Santiago de Compostela: Universidad de Santiago de Compostela.

ROMERO, Luis Alberto (1984): «Urbanización y sectores populares: Santiago de Chile, 1830-1875». EURE, Revista de Estudios Urbanos y Regionales, Vol. XI, $N^{\circ} 31$. Santiago: PUC.

- (1987): «Los sectores populares en las ciudades latinoamericanas del siglo XIX: la cuestión de la identidad». Desarrollo Económico, Vol. 27, №106. Santiago.

_ (1989): «¿Cómo son los pobres? Miradas de la élite e identidad popular en Santiago hacia 1870». Opciones $\mathrm{N}^{\circ} 16$. Santiago.

- (1997): ¿Qué hacer con los pobres? Élites y sectores populares en Santiago de Chile, 1840-1895. Buenos Aires: Editorial Sudamericana.

RUdÉ, GEORGES (1988): La Europa revolucionaria: 1783-1815. Madrid: Siglo XXI.

_ (1998): La multitud en la historia. Los disturbios populares en Francia e Inglaterra, 1730-1848. México: Siglo XXI.

- (2004): La revolución francesa. Buenos Aires: Vergara.

SALAZAR, GABRIEL (1985): Labradores, peones y proletarios. Formación y crisis de la sociedad popular chilena del siglo XIX. Santiago: Ediciones SUR.

— (1990): «Ser niño 'huacho' en la historia de Chile (siglo XIX)». Proposiciones No19. Santiago: Ediciones SUR. 
_ (1991): «Empresariado popular e industrialización: la guerrilla de los mercaderes (Chile, 1830-1855)». Proposiciones №20. Santiago: Ediciones SUR.

SALINAS, RENÉ (1996): «La transgresión delictiva de la moral tradicional y sexual y su represión en Chile tradicional». Contribuciones Científicas y Tecnológicas $\mathrm{N}^{\circ} 114$. Santiago: Departamento de Historia, USACH.

_ (1998a): «Relaciones afectivas articuladas en torno al espacio doméstico en la aldea chilena. 1750-1850». En Casa, vecindario y cultura en el siglo XVIII. México: VI Simposio de Historia de las Mentalidades, Instituto Nacional de Antropología e Historia.

_ (1998b): «Espacio doméstico, solidaridades y redes de sociabilidad aldeana en Chile tradicional, 1750-1880». Contribuciones Científicas y Tecnológicas $\mathrm{N}^{\circ} 118$. Santiago: Departamento de Historia, USACH.

— e IGOR GOICOVIC (2000): «Las reformas borbónicas y la construcción de sociabilidad en las villas coloniales del Chile tradicional (1750-1810)». Actas del Simposio Internacional El impacto de las reformas borbónicas en la estructura de las ciudades. Un enfoque comparativo. México: Gobierno de la Ciudad de México, Vocalía Ejecutiva.

SANMARTÍn, JosÉ (2002): La mente de los violentos. Barcelona: Ariel.

Sodré, MuÑIZ (2001): Sociedad, cultura y violencia. Buenos Aires: Grupo Editorial Norma.

Stein, William (1988): El levantamiento de Atusparia. Lima: Mosca Azul Editores.

SURIANO, JUAN (compilador) (2000): La cuestión social en Argentina, 1870-1943. Buenos Aires: Editorial La Colmena.

Tenenti, Alberto (1999): De las revueltas a las revoluciones. Barcelona: Crítica.

THOMPSON, EDWARD (1984): Tradición, revuelta y conciencia de clase. Estudios sobre la crisis de la sociedad preindustrial. Crítica: Barcelona.

Thomson, IAn y Dietrich Angerstein (1997): Historia del ferrocarril en Chile. Santiago: DIBAM.

VALENCia CASTAÑEDA, LuCía (1999): «Diversión popular y moral oligárquica: entre la barbarie y la civilización. Valparaíso, 1850-1880». Contribuciones Cientificas y Tecnológicas $\mathrm{N}^{\mathrm{0}} 122$. Santiago: Departamento de Historia, USACH.

Valenzuela Márquez, Jaime (1991): Bandidaje rural en Chile central. Curicó, 1850-1900. Santiago: DIBAM.

VÁsQueZ, EMILIo (1976): La rebelión de Juan Bustamante. Lima: Juan Mejía Barca Editorial.

VAyssiere, Pierre (1980): Un siècle de capitalisme minier au Chili, 1830-1930. París: CNRS.

Vial, GonZALO (1981-1996): Historia de Chile (1891-1973), 4 Volúmenes. Santiago: Editorial Zig-Zag.

Vv.AA. (1987): Movimientos populares en la Historia de México y América Latina. México: UNAM.

WAlter, Benjamín (1998): Para una crítica de la violencia y otros ensayos. Madrid: Taurus.

ZulaikA, Joseba (1993): «Violencia, texto y parodia». Antropología Nº. Madrid. 